\begin{tabular}{|l|l|l||}
\hline \multicolumn{2}{|c|}{ PublisherInfo } \\
\hline \hline PublisherName & $:$ & BioMed Central \\
\hline \hline PublisherLocation & $:$ & London \\
\hline \hline PublisherImprintName & $:$ & BioMed Central \\
\hline \hline
\end{tabular}

\title{
BRCA1 complex contains multiple DNA repair proteins
}

\begin{tabular}{|l|l|l||}
\hline \multicolumn{2}{|c||}{ ArticleInfo } \\
\hline \hline ArticleID & $:$ & 3714 \\
\hline \hline ArticleDOI & $:$ & $10.1186 /$ bcr-2000-66677 \\
\hline \hline ArticleCitationID & $:$ & 66677 \\
\hline \hline ArticleSequenceNumber & $:$ & 80 \\
\hline \hline ArticleCategory & $:$ & Paper Report \\
\hline \hline ArticleFirstPage & $:$ & 1 \\
\hline \hline ArticleLastPage & $:$ & 4 \\
\hline \hline & & RegistrationDate : 2000-5-19 \\
\hline ArticleHistory & $:$ & OnlineDate \\
\hline \hline ArticleCopyright & $:$ & Current Science Ltd2000-5-19 \\
\hline \hline ArticleGrants & $:$ & \\
\hline \hline ArticleContext & $:$ & 1305822 \\
\hline \hline
\end{tabular}


David Bertwistle, Aff1

Aff1 Institute of Cancer Research, London

\section{Keywords}

ATM, BLM, BRCA1, DNA Repair, MLH1, MSH2, MSH6, RAD50, replication, RFC

\section{Introduction}

Disruption of both copies of the breast cancer susceptibility gene, BRCA1, leads to genetic instability. This is thought to reflect the role of BRCA1 in the homologous recombination mediated repair of DNA double-strand breaks. Many other proteins are involved in DNA repair and some of these are also encoded by cancer predisposition genes. Knowing which of these proteins interacts with BRCA1 should deepen our understanding of the role of BRCA1 in DNA repair.

\section{Aims}

To identify BRCA1-associated proteins, as a way of understanding the role of BRCA1 in homologous recombination mediated repair of DNA double-strand breaks.

\section{Comments}

This paper adds BLM, MSH2, MSH6, MLH1 and replication factor C (RFC) subunits p140, p37 and p34 to the list of published BRCA1-associated proteins (see additional information). BRCA1 has previously been shown to interact with Ataxia-Telangiectasia mutation (ATM) (Cortez et al, Science 1999, 286:1162-1166 [Abstract]) and the RAD50-MRE11-NBS1 complex (Zhong et al, Science 1999, 285:747-750 [Abstract]) and those results are confirmed in this study. All of these proteins are involved in the recognition of abnormal DNA structures and several are involved in DNA replication-associated repair. These data suggest a role for this BRCA1-associated complex in the maintenance of genomic stability during DNA replication. 


\section{Methods}

BRCA1 was immunoprecipitated from HeLa cell nuclei using two rabbit polyclonal antibodies raised against glutathione- $S$-transferase (GST)-BRCA1 fusion proteins containing amino acids 1021-1552 and 1501-1861 of BRCA1, and the commercial antibody C-20, raised against a C-terminal epitope of BRCA1.

\section{Results}

A total of 40 proteins appearing to specifically bind BRCA1 were identified. Only those involved in DNA repair are described further in this paper. These were RAD50, ATM, BLM, MSH6, MSH2, MLH1 and three subunits of the RFC complex (p140, p37 and p34).

Nearly all of these proteins can co-immunoprecipitate each other. Fractionation of nuclear extracts supported this data. All the BRCA1-associated DNA repair proteins were detected in multiple fractions and all were found to co-elute with BRCA1 in a complex of greater than $2 \mathrm{MDa}$, that the authors name BASC (BRCA1-associated genome surveillance complex).

Colocalisation of BASC components was analysed by immunofluorescence. Hydroxyurea treatment, which causes replication arrest, was found to increase the colocalisation of BLM, the RAD50-MRE11-NBS1 complex and BRCA1 at nuclear foci in cells treated during mid to late S or G2 phase. These foci were found to co-stain with proliferating cell nuclear antigen (PCNA), indicating that they are located at replication forks. Contrary to a previous report (Zhong et al, Science 1999, 285:747-750 [Abstract]) no defect in RAD50 foci formation was observed in BRCA1 mutant HCC1937 cells.

\section{Discussion}

Neither BRCA2 nor RAD51, which have previously been reported to interact with BRCA1, were found to associate with BRCA1 in this study. This might be because they were displaced by the antibodies used, or because they are substoichiometric components of BASC that were undetectable by Coomassie blue staining.

All the BRCA1-associated proteins described here have in common an ability to bind to abnormal DNA structures, indicating that BASC might be involved in sensing damaged DNA. Furthermore, they are all known to have some role in postreplication DNA repair. The colocalisation of BRCA1 and other BASC components to PCNA-positive replication forks after hydroxyurea-induced replication arrest suggests that BASC could be involved in resolving aberrant DNA structures that arise during DNA replication. 
The association of BRCA1 with MSH2-MSH6 and MLH1 may explain the role of BRCA1 in transcription coupled repair of oxidation induced damage (Gowen et al, Science 1998, 281:1009-1012 [Abstract])

\section{Additional information}

RAD50 is part of the RAD50-MRE11-NBS1 complex, which functions in homologous recombination and nonhomologous end joining, both used in DNA double-strand break repair. ATM is encoded by the ATM gene, which is responsible for the cancer predisposition syndrome, ataxia telangiectasia. BLM is a RecQ DNA helicase, encoded by the BLM gene which is mutated in Blooms' syndrome. MSH2, MSH6 and MLH1 are encoded by mismatch-repair genes and mutations in MSH2 and MLH1 are linked to hereditary nonpolyposis colorectal cancer.

\section{References}

1. Wang Y, Cortez D, Yazdi P, Neff N, Elledge SJ, Qin J: BASC, a super complex of BRCA1-associated proteins involved in the recognition and repair of aberrant DNA structures. Genes Dev. 2000, 14: 927-939. 